\title{
Enhancement of THD in HVDC System using Shunt Active Power Filters
}

\author{
K.Srinivas \\ Assistant Professor \\ JNTUH College of Engineering \\ Karimnagar, AP,India.
}

\author{
S.S. Tulasi Ram, Ph.D \\ Professor \\ JNTUH College of Engineering \\ Hyderabad, AP, India
}

\begin{abstract}
The increasing use of power electronic based loads (adjustable speed drives, switch modern power supplies, etc) to improve system efficiency and controllability is increasing concern for harmonic distortion levels in end use facilities and on overall power system. The Active Power Filter uses power electronic switching to generate harmonic currents that cancel harmonic content from non - linear loads. The basic principle of Shunt Active Power Filter is that it generates a current equal and opposite in phase to the harmonic current drawn by the load and injects it at point of common coupling there by forcing currents to be pure sinusoidal. The active filter configuration implemented in this paper is based on the pulse - width modulated (PWM) voltage source inverter (VSI) that interfaces to the system through filter. In this configuration the filter is connected is in parallel for harmonic current cancellation so that the current being supplied from the source is sinusoidal. The control scheme of this three phase shunt Active Power Filter is based on the instantaneous Id - Iq theory. The compensating current controlled is achieved is with the VSI in the current controlled mode, the desired by accurately controlling the switching of the IGBTs through hysteresis current controller.
\end{abstract}

Theoretical analysis and spectrum analysis have been completed. To validate the theoretical analysis simulation is conducted for such developed model and control schemes under MATLAB/Simulink..

\section{Keywords}

Power Quality, Harmonics, Total Harmonics Distortion.

\section{INTRODUCTION}

The increasing use of power electronic based loads (adjustable Speed drives, Switch mode power supplies, etc) to improve system efficiency and Controllability is increasing concern for harmonic distortion levels in end use facilities and on overall power system. The application of passive tuned filters creates new system resonances, which are dependent on specific system conditions. In addition, passive filters often need to be significantly overrated to account for possible harmonic absorption from power system. Passive filter ratings must be coordinated with reactive powerrequirements of the loads and it is often difficult to design the filter to avoid leading power factor Operation for some load conditions. A number of low-power electronic based appliances such as TV sets, personal computers, and adjustable speed pumps generate a large amount of harmonic current in power systems even though a single low power electronic based appliance, in which a single-phase diode rectifier with a dc link capacitor is used as utility interface, produces a negligible amount of harmonic current. Three-phase diode or thyristor rectifiers and cycloconverters for industry applications, also generate a large amount of harmonic current [1], [2]. Voltage distortion or harmonics resulting from current harmonics produced by power electronic equipment has become a serious problem to be solved in many countries. Power system harmonics are not a new problem. Due to the widespread proliferation of nonlinear distorting loads such as power-electronic controlled devices, the problems caused by harmonics are of increasing importance. Unlike the conventional load, the powerelectronic device controls the flow of power by chopping. Flattening, or shaping the waveforms of the voltage and current. Therefore, harmonics are generated during the process. These waveform distortions can cause problems for neighboring loads, and they tend to have an overall opposite effect on the quality of electric power. A concept that can improve the power quality is the active power filter. This type of filters can meet diverse load conditions. In addition to improve power factor, it also appears to be an attractive and viable method for reducing voltage and current harmonic distortion or other power quality problems such as flicker. The active power filter improves the system power quality by injecting equal-but opposite currents to compensate harmonic distortion and reactive power. Ideally, this active power filter should monitor and minimize voltage and went distortion of its connected load. In the past some active power filters were designed based on the conventional IRP theory. However, the IRP theory-based active filter cannot compensate the harmonic distortion and does not function properly. In order to improve the drawbacks of the conventional IRP theory, instantaneous active and reactive power theory-based the control strategy of the active power filter proposed and implemented in Mat lab/Simulink. It is found that proposed instantaneous active and reactive current id -Iq theory-based three-phase shunt active power filter is to be an effective device to reduce harmonic current and THD.

The objective of the electric utility is to deliver sinusoidal voltage at fairly constant throughout the system. The objective is complicated by the fact that there are loads on the system that produces harmonic currents (non-linear loads).

\section{ACTIVE TOPOLOGIES} POWER

FILTER

There are two approaches to the mitigation of power quality problems. The first approach is called load conditioning, which ensures that the equipment is less sensitive to power disturbances, allowing the operation even under significant voltage distortion. The other solution is to install lineconditioning systems that suppress or counteracts the power system disturbances. Active power filters offer a flexible and versatile solution to voltage quality problems. Currently they are based on PWM converters and connect to low and 
medium voltage distribution system in shunt or in series. Series active power filters must operate in conjunction with shunt passive filters in order to compensate load current harmonics. Shunt active power filters operate as a controllable current source and series active power filters operates as a controllable voltage source. Both schemes are implemented preferable with voltage source PWM inverters, with a dc bus having a reactive element such as a capacitor. Active power filters can perform one or more of the functions required to compensate power systems and improving power quality. As it will be illustrated in this paper, their performance depends on the power rating and the speed of response. The selection of the type of active power filter to improve power quality depends on the source of the problem as can be seen in Table 1

Topology I: shunt active power filter system.

Topology II: series active power filter system.

Topology III: Hybrid active power filter system.

Table 1 ACTIVE POWER FILTER SOLUTION TO POWER QUALITY PROBLEMS

\begin{tabular}{|l|l|l|}
\hline $\begin{array}{l}\text { Active Filter } \\
\text { Connection }\end{array}$ & Load on AC Supply & $\begin{array}{l}\text { AC Supply on } \\
\text { Load }\end{array}$ \\
\hline Shunt & $\begin{array}{l}\text {-Current Harmonic } \\
\text { Filtering. } \\
\end{array}$ & \\
& -Reactive current \\
compensation. & \\
& -Current unbalance. & \\
& -Voltage Flicker. & \\
\hline Series & -Current Harmonic & -Voltage \\
& Filtering. & sag/swell. \\
& -Reactive current & -Voltage \\
& compensation. & Unbalance \\
& -Current unbalance. & -Voltage \\
& distortion \\
& -Voltage Flicker. & -Voltage \\
& -Voltage unbalance & interruption \\
& & -Voltage flicker \\
& & -Voltage notching \\
\hline
\end{tabular}

\subsection{Shunt active power filter $[3,4,5$, and 7$]$}

This class of filters constitutes the most important and widely used filter configuration in industrial process. It is connected in parallel to the main power circuit as shown in Fig.2.1. The concept of the shunt active power filter is based on harmonic cancellation through the act of injecting equal and opposite harmonic currents into the supply line by means of solid-state converter circuits. These filters are voltage source type or current source type as shown in Fig. 2.2, respectively. Normally these filters are connected in parallel with the load, and carry only a fraction of the fundamental current. Furthermore, they can be designed to provide compensation for all of the system non-linearties at the point of common coupling (PCC) under distorted and non-distorted supply.

These filters have disadvantages of injection of switching frequency harmonics in the system. Due to the need of high switching frequency fully gate controlled devices these filters are limited to low and medium power range only.

Shunt active power filter compensate current harmonics by injecting equal-but-opposite harmonic compensating current. In this case the shunt active power filter operates as a current source injecting the harmonic components generated by the load but phase shifted by 180 o. This principle is applicable to any type of load considered a harmonic source. Moreover, with an appropriate control scheme, the active power filter can also compensate the load power factor. In this way, the power distribution system sees the non linear load and the active power filter as an ideal resistor. The current compensation characteristic of the shunt active power filter is shown in Fig.2.1

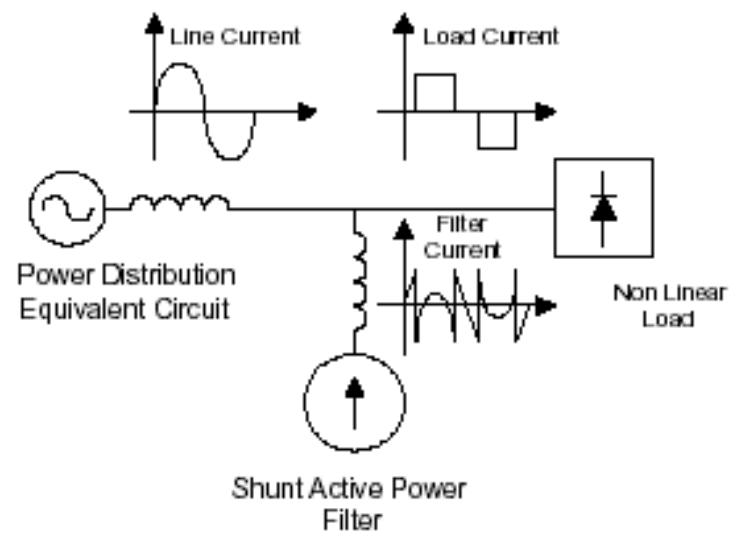

Fig. 2.1 Shunt active power filtering

\subsubsection{Power circuit Topology [8]}

Shunt active power filters are normally implemented with pulse-width modulated voltage source inverters. In this type of applications, the PWM-VSI operates as a current controlled voltage source. Traditionally, 2 level PWM-VSI have been used to implement such system.

However, in the past years multilevel PWM voltage source inverters have been proposed to develop active power filters for medium voltage applications. Also, active power filters implemented with multiple VSI connected in parallel to a dc bus but in series through a transformer or in cascade has been proposed in the technical literature.

The use of VSI connected in cascade is an interesting alternative to compensate high power non-linear load. The use of two PWM-VSI of different rated power allows the use of different switching frequencies, reducing switching stresses and commutation losses in the overall compensation system. In recent years, there has been an increasing interest in using multilevel inverters for high power energy conversion, especially for drives and reactive power compensation. Multilevel PWM inverters can be connected to high voltage source without a coupling transformer. The use of neutralpoint-clamped (NPC) inverters allows equal voltage shearing of the series connected devices in each phase. However, the neutral point potential deviates, resulting in an excess voltage stress to either the upper or lower set of devices. Basically, multilevel inverters have been developed for applications in high voltage ac motor drives and static VAR compensation. For these types of applications, the output voltage of the multilevel inverter must be able to generate an almost sinusoidal output current. In order to generate a near sinusoidal output current, the output voltage should not contain low frequency harmonic components. 


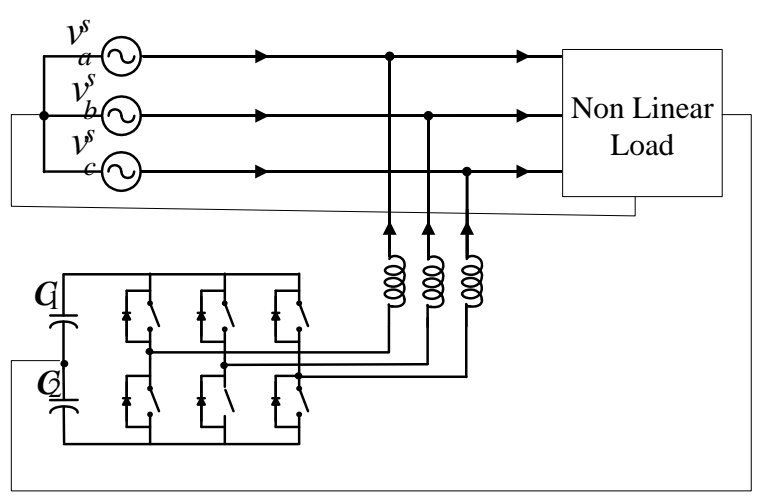

Fig. 2.2 Shunt active power filter topologies implemented with PWM voltage-source inverters.

For active power filter applications the three levels NPC inverter output voltage must be able to generate an output current that follows the respective reference current which contain the harmonic and reactive component required by the load. The power circuit topology of an active power filter implemented with a Neutral-Point- Clamped voltage-source inverter is shown in Fig. 2.3. The three levels NPC voltagesource inverter is connected in parallel through a link reactor to the power distribution system.

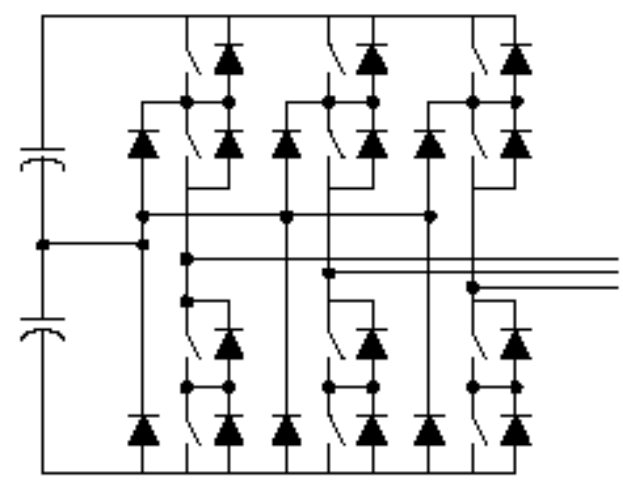

Fig. 2.3 an active power filter implemented with a three level NPC voltage-source inverter

\subsection{Series Active power filters:}

The active power filters in this configuration produces a PWM voltage waveform, which is added/subtracted on the instantaneous basis, to force the supply voltage to maintain pure sinusoidal waveform across the load. The line diagram of power circuit configuration is shown in Fig. 2.4. The inverter configuration accompanying such a system is a voltage fed inverter without any current control loop. It is well known that series active power filters compensate current system distortion caused by non-linear loads by imposing a high impedance path to the current harmonics which forces the high frequency currents to flow through the LC passive filter connected in parallel to the load [5]. The high impedance imposed by the series active power filter is created by generating a voltage of the same frequency that the current harmonic component that needs to be eliminated. Compensating the fundamental frequency negative and zero sequence voltage components of the system correct voltage unbalance.

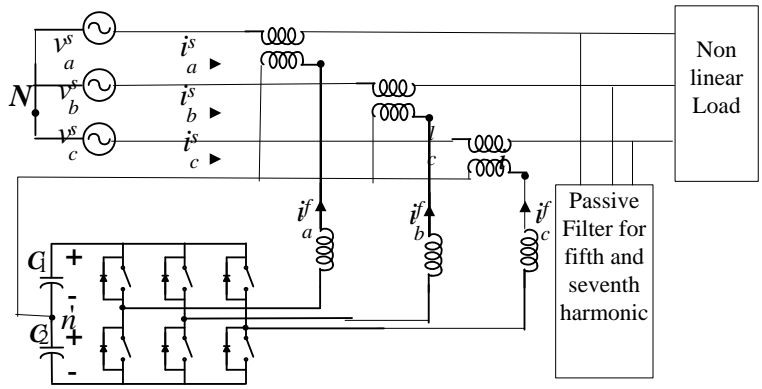

Fig.2.4The proposed series active power filter topology.

\subsection{Combination of series-shunt active power filters $[7,8]$ :}

Fig.2.5 shows the line diagram of the combination of the shunt active and series active filter. The major functions of the series filter are to provide voltage harmonic isolation between the supply side and the load side, voltage regulation, voltage flicker and/or imbalance compensation at the point of common coupling (PCC). The main functions of the shunt active filter is to act as harmonic sink, however this may also be used to provide reactive power compensation and dc link voltage regulation between the filters. This combination is generally known as "Unified Power Flow Controller (UPFC)" or "Unified Power Quality Conditioner (UPQC)". Active power filters can be used with passive filters improving compensation characteristics of the passive filter, and avoiding the possibility of the generation of series or parallel resonance.

By controlling the amplitude of the voltage fundamental component across the coupling transformer, the power factor of the power distribution system can be adjusted. However, the control of the load power factor imposed a higher voltage across the filter capacitor. This consideration has to be considered when the filter capacitor is specified. This type of configuration is very convenient for compensation of high power medium voltage non linear loads, such as large power ac drives with cycloconverters or high power medium voltage rectifiers for application in electro wining process or for compensation of arc furnace. In all these applications passive filters do not have enough compensation capability to reduce current harmonics in order to satisfy IEEE Std.519.

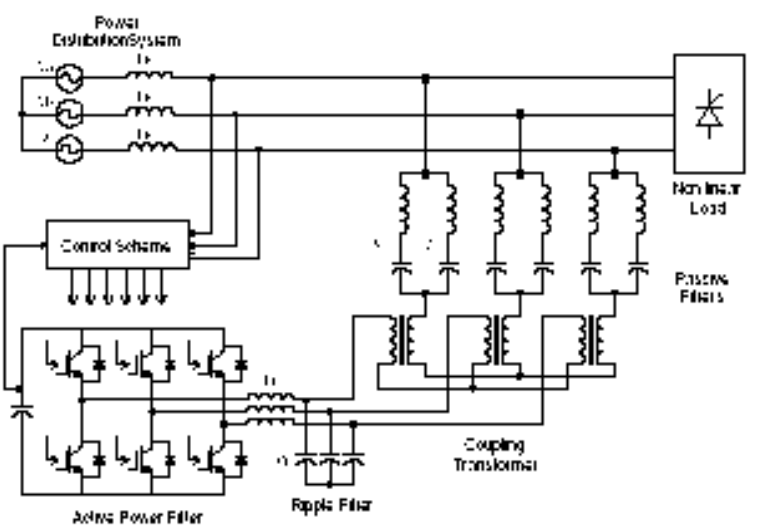

Fig.2.5The hybrid active power filter configuration. 


\section{CONTROL OF SHUNT ACTIVE POWER FILTER}

\subsection{Instantaneous Active and Reactive Current Component Id-Iq [9]}

The basic principle of Shunt active filter is that it generates a current equal and opposite in Polarity to the harmonic current drawn by the load and injects it to the point of coupling there by forcing the source current to be pure sinusoidal

The first transform is to move from a 3-axis, 2-dimensional coordinate system referenced to the stator of the motor to a 2axis system also referenced to the stator. The process is called the Clarke Transform. At this point you have the stator current phasor represented on a 2-axis orthogonal system with the axis called $\alpha-\beta$. The next step is to transform into another 2axis system that is rotating with the rotor flux. This transformation uses the Park Transform, as illustrated in

Fig.3.1. This 2-axis rotating coordinate system is called the d$\mathrm{q}$ axis. From this perspective the components of the current Phasor in the $\mathrm{d}-\mathrm{q}$ coordinate system are time invariant. Under steady state conditions they are DC values. The stator current component along the $\mathrm{d}$ axis is proportional to the flux, and the component along the $\mathrm{q}$ axis is proportional to the rotor torque. Now that you have these components represented as DC values you can control them independently with classic PI control loops.

\subsection{Parks Transform}

In this method the currents Ici are obtained from the instantaneous active and reactive current components $I \ell \mathrm{d}$ and I $\ell \mathrm{q}$ of the nonlinear load. In the same way, the mains voltages vi and the polluted currents $I \ell i$ in $\alpha \beta$ as in the previous method by (3.1) and (3.2). However, the load current components are derived from a synchronous reference frame based on the Park transformation, where represents the instantaneous voltage vector angle (5.3.6)

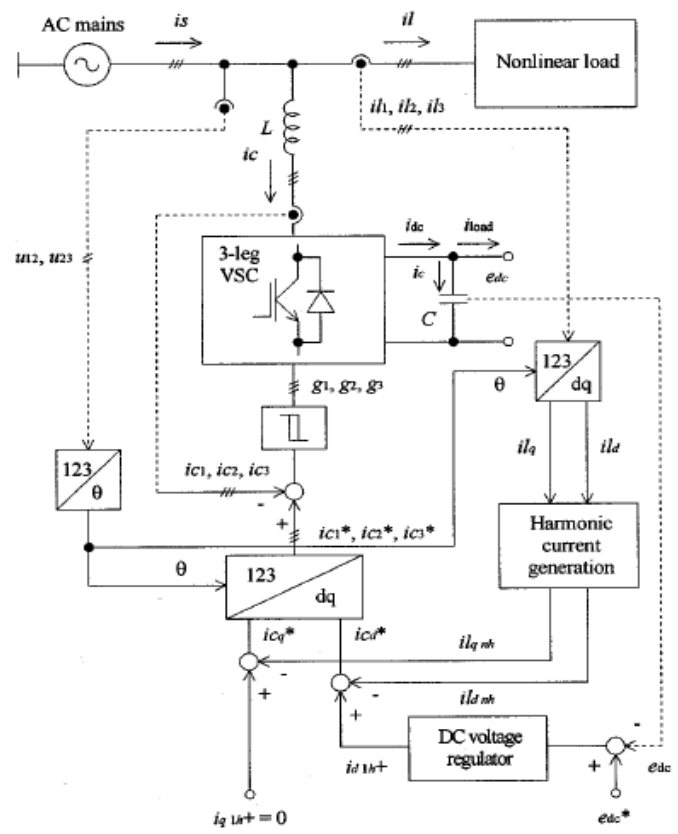

Fig. 3.1 AF control system based on the instantaneous active and reactive current component Id - Iq method

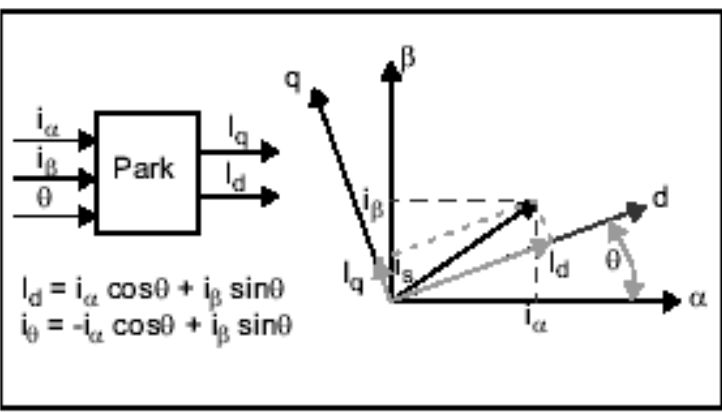

Fig. 3.2 parks transform

$$
\left[\begin{array}{l}
i_{l d} \\
i_{l q}
\end{array}\right]=\left[\begin{array}{cc}
\cos \theta & \sin \theta \\
-\sin \theta & \cos \theta
\end{array}\right]\left[\begin{array}{l}
i_{l \alpha} \\
i_{l \beta}
\end{array}\right], \theta=\tan ^{-1} \frac{u_{\beta}}{u_{\alpha}}
$$

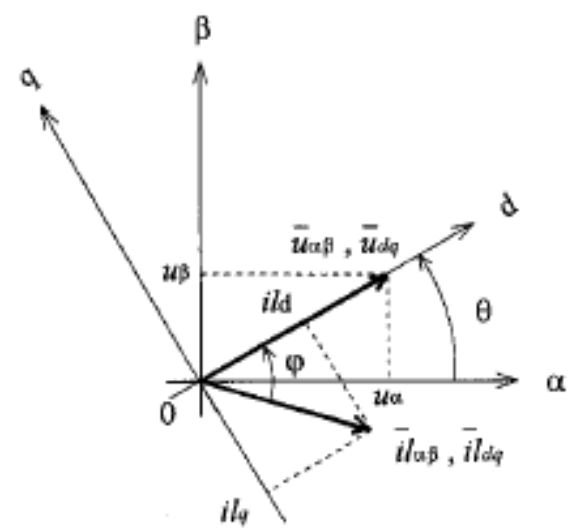

Fig. 5.4 depicts the voltage and current space vectors in the stationary $\alpha \beta$ and rotating frames $d q$.

Under balanced and sinusoidal mains voltage conditions angle $\theta$ is a uniformly increasing function of time. This transformation angle is sensitive to voltage harmonics and unbalance, therefore $\mathrm{d} \theta / \mathrm{dt}$ may not be constant over a mains period. With transformation the direct voltage component is $\left|\overline{u_{d q}}\right|=\left|\overline{u_{\alpha \beta}}\right|=\sqrt{u_{\alpha}^{2}+u_{\beta}^{2}}$ and the quadrature voltage component is always null, $\mathrm{Uq}=0$, so due to geometric relations (5.3.6) becomes

$\left[\begin{array}{l}i_{c \alpha} \\ i_{c \beta}\end{array}\right]=\frac{1}{\sqrt{u_{\alpha}^{2}+u_{\beta}^{2}}}\left[\begin{array}{cc}u_{\alpha} & -u_{\beta} \\ u_{\beta} & u_{\alpha}\end{array}\right]\left[\begin{array}{l}i_{c d} \\ i_{c q}\end{array}\right]$

One of the characteristics of both methods is that the compensating currents are calculated directly from the mains voltages, enabling the methods to be frequency-independent. Avoiding the use of a PLL a large frequency operating range can be achieved limited chiefly by the cutoff frequency of the current control system (VSC and current controller). Furthermore, under unbalanced and nonsinusoidal mains voltage conditions, a large number of synchronization problems are avoided especially if a PLL is synthesized with a fast dynamic response. 


\subsection{Inverse Park}

After the PI iteration you have two voltage component vectors in the rotating $\mathrm{d}-\mathrm{q}$ axis. You will need to go through complementary inverse transforms to get back to the 3-phase motor voltage. First you transform from the 2 -axis rotating $d-$ $\mathrm{q}$ frame to the 2-axis stationary frame $\alpha-\beta$. This transformation uses the Inverse Park Transform, as illustrated in Figure 5.5

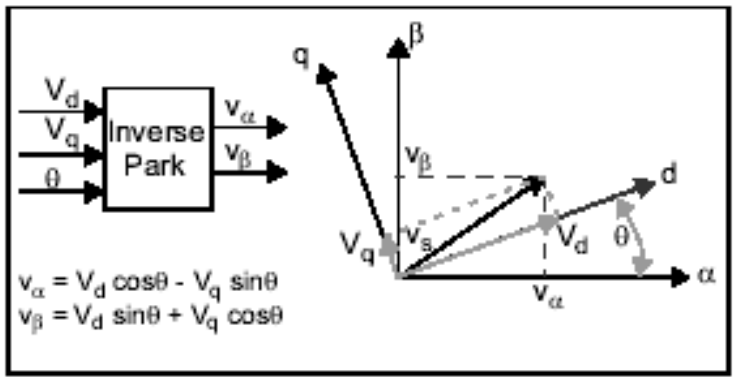

Fig. 5.5 Inverse Park Transform

A Park current calculator performs the direct and inverse transformations described previously. In the experimental prototype the angle $\theta$ is calculated by (3.2), however $u \alpha$ and $\mathrm{u} \beta$ are derived form the mains line-to-line voltages $\mathrm{u}_{12}$ and $\mathrm{u}_{23}$.

$$
\left[\begin{array}{l}
u_{\alpha} \\
u_{\beta}
\end{array}\right]=\sqrt{\frac{2}{3}}\left[\begin{array}{cc}
1 & \frac{1}{2} \\
0 & \frac{\sqrt{3}}{2}
\end{array}\right]\left[\begin{array}{l}
u_{12} \\
u_{23}
\end{array}\right]
$$

The zero current components are null, therefore the inverse and direct Park transformations are obtained from (3.3) and (3.4), respectively.

The zero current components are null, therefore the inverse and direct Park transformations are obtained from (3.5).

$$
\begin{aligned}
& {\left[\begin{array}{l}
i_{l d} \\
i_{l q}
\end{array}\right]=\sqrt{2}\left[\begin{array}{cc}
\cos \left(\theta+\frac{\Pi}{3}\right) & \sin \theta \\
-\cos \left(\theta+\frac{\Pi}{3}\right) & \cos \theta
\end{array}\right]\left[\begin{array}{l}
i_{l 1} \\
i_{l 2}
\end{array}\right] \ldots \ldots \ldots \ldots \ldots(3.4)} \\
& {\left[\begin{array}{l}
i_{c 1} \\
i_{c 2}
\end{array}\right]=\sqrt{\frac{2}{3}}\left[\begin{array}{cc}
\cos (\theta) & -\sin \theta \\
-\cos \left(\theta+\frac{\Pi}{3}\right) & \sin \left(\theta+\frac{\Pi}{3}\right)
\end{array}\right]\left[\begin{array}{l}
i_{c d} \\
i_{c q}
\end{array}\right] \ldots \ldots \ldots(3.4)}
\end{aligned}
$$

In Fig. 5.5 a block diagram of the inverse Park current calculation and the Park current calculator implementation is presented. The measured voltages u12 and u 23 pass through anti-aliasing filters and voltage limiters before digital conversion.

\subsection{Harmonic Current Generation [5]}

By the inverse Park transformation the first harmonic load current of positive sequence is transformed to dc quantities $\mathrm{i} \ell \mathrm{dq} 1 \mathrm{~h}+$. These represent the harmonic current system that must be preserved in the mains. The ac components of the load current must be injected by the AF. These ac quantities are i $\mathrm{ddq}$ which derive from the load currents. The AHPF presented in Fig. 5.6. Low-pass Butterworth fourth-order switched-capacitor filters are used. The cutoff frequency chosen is $f c=f / 2$. This assures a small phase shift in harmonics and a sufficiently fast transient response in the AF harmonic compensation. The fourth-order AHPF gives the best performance. The AHPF presents four times less slope in the rejection band than the HPF $(80 \mathrm{~dB} / \mathrm{dec})$, its phase response is very close to zero in the harmonic load current spectra. This is very important especially in the compensation of low frequency current components (e.g. second order harmonic current of negative sequence).

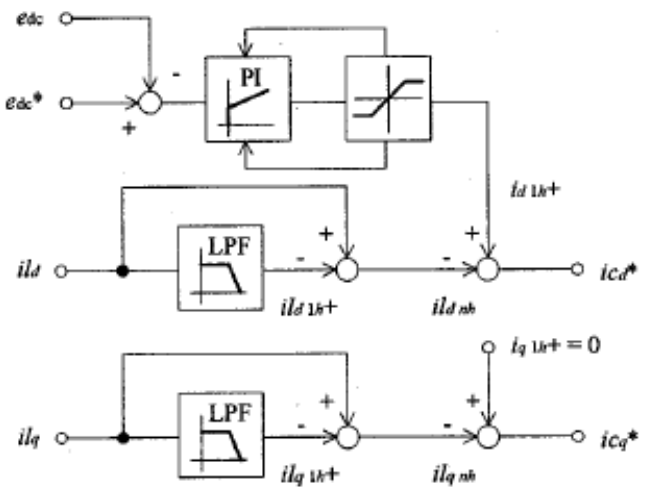

Fig. 5.6 block diagram of harmonic current generation

\section{SIMULATION MODELS OF NON- LINEAR LOAD SYSTEMS}

\subsection{Phase Source Driving a Diode Rectifier Resistive Load}

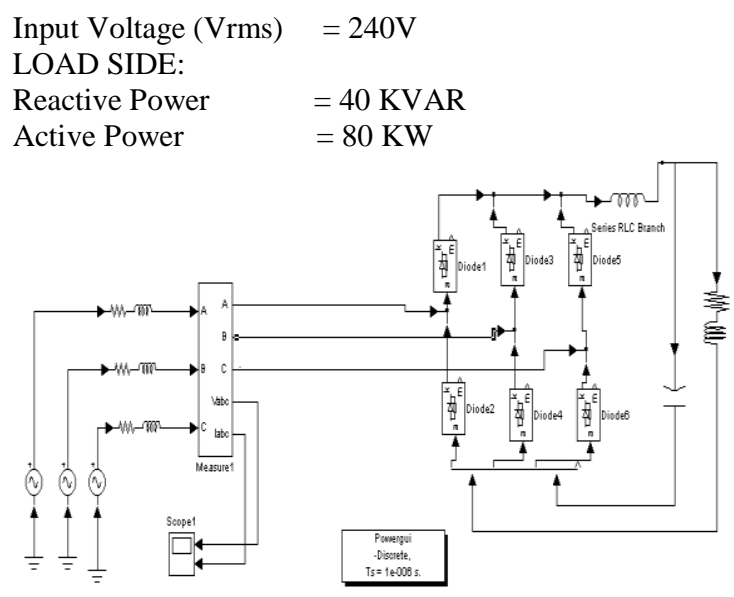

Fig. 4.1 phase source driving a diode rectifier load

Single phase diode rectifier load implemented in Matlab/Simulink shown in Fig. 4.1 and Input Voltage and Current Wave Forms for diode model shown in Fig. 4.3, the THD for input current wave forms found using FFT analysis. The diode rectifier with shunt active power filters shown in Fig. 4.4, input Voltage and Current Waveforms with THD for diode rectifier with APF shown in Fig. 4.5 and Fig. 4.6. 


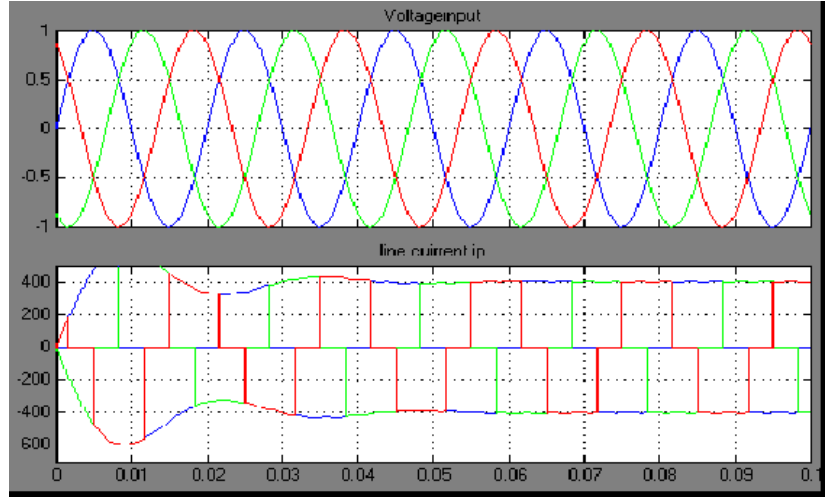

Fig. 4.2 Input Voltage and Current Wave Forms for diode model
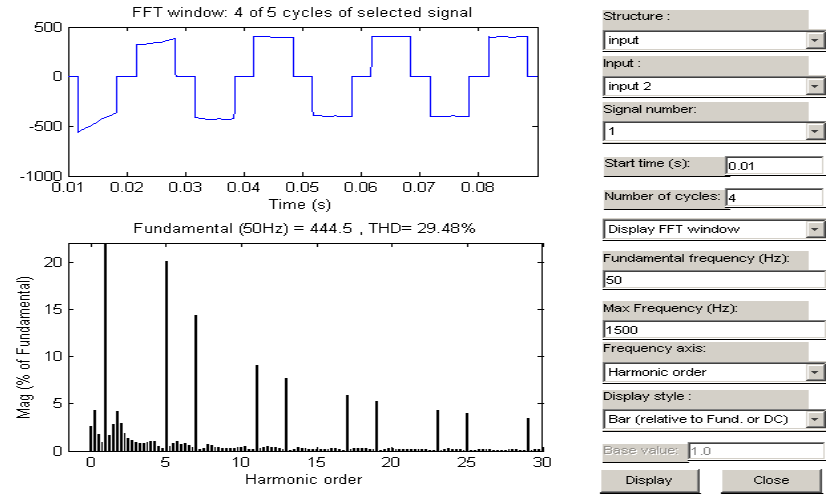

Fig. 4.3 FFT of THD for diode model

\subsection{Non Linear Load Systems with 3-Phase Shunt Active Power Filter}

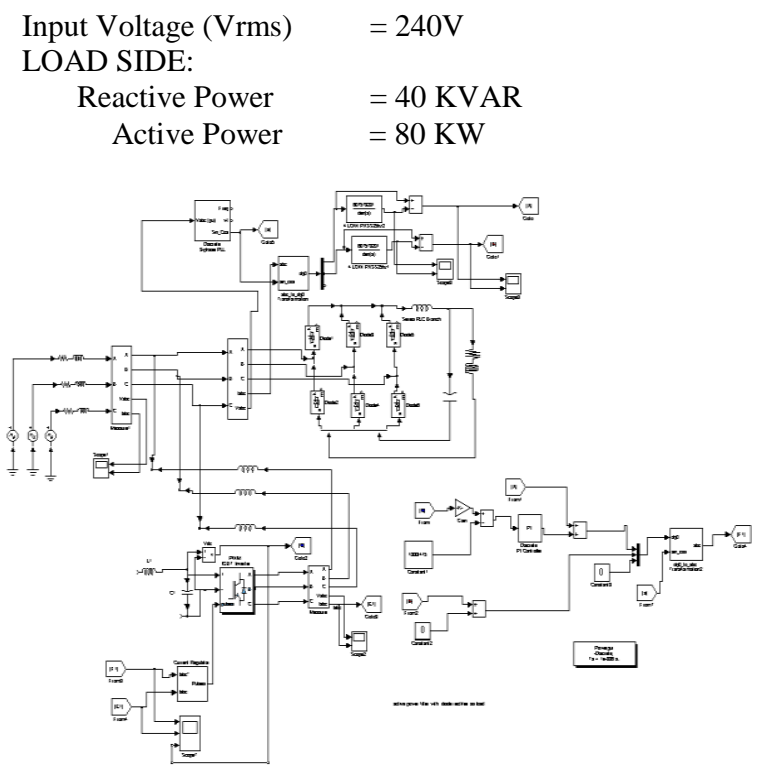

Fig. 4.4 Diode rectifier with Shunt APF Control Strategy

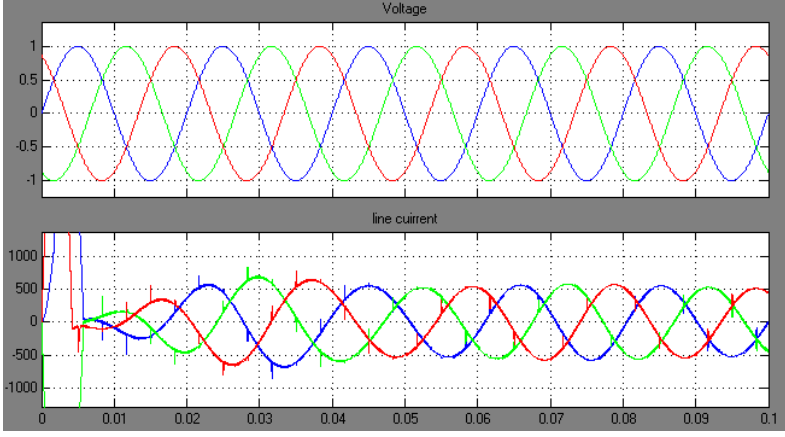

Fig. 4.5 Voltage and Current Waveforms for diode rectifier with APF
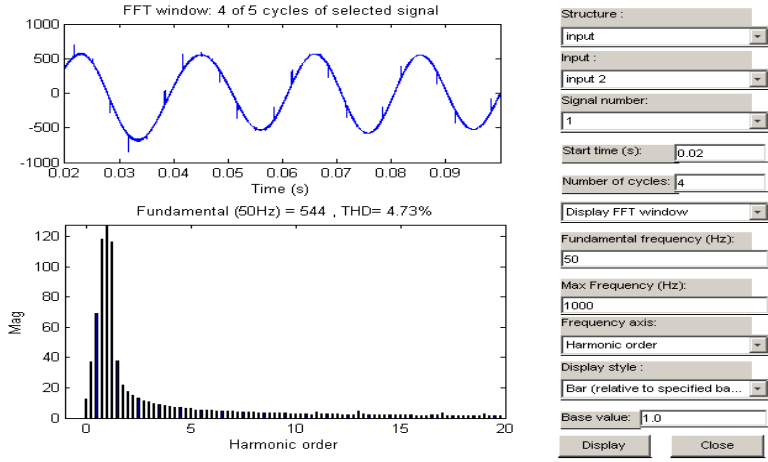

Fig. 4.6 THD Values of current waveform for diode rectifier with APF

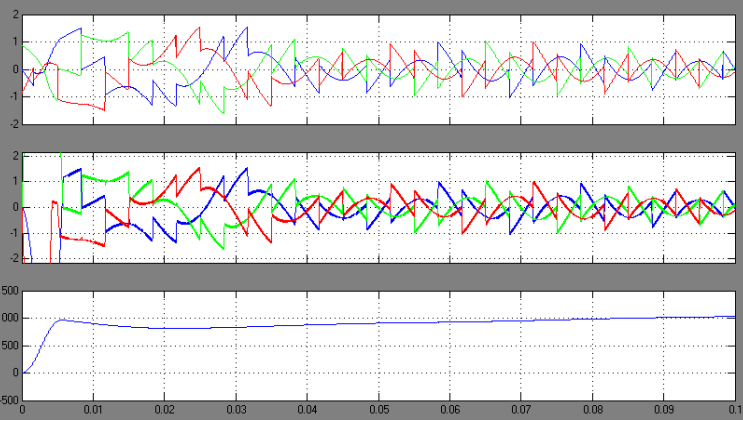

Fig. 4.7 Inverter gating, reference and capacitor Current wave forms with APF
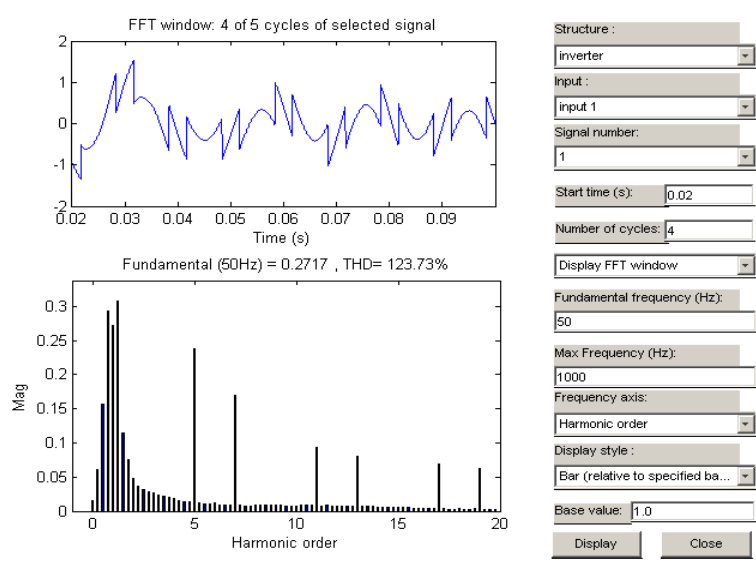

Fig. 4.8 Inverter reference current for rectifier load with APF 

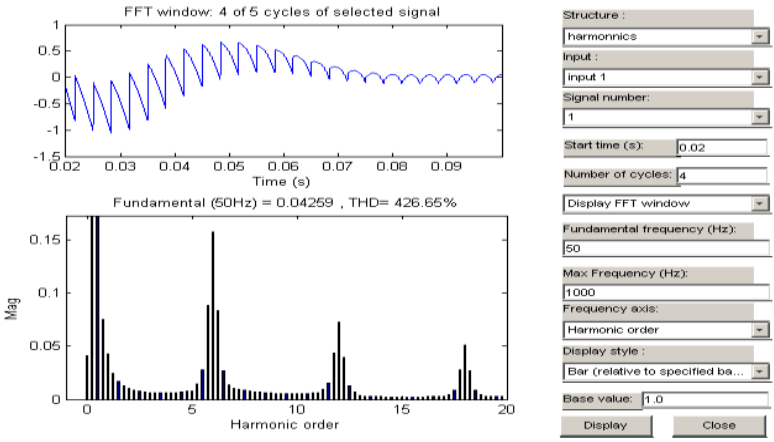

Fig. 4.9 Id harmonics for rectifier load with APF
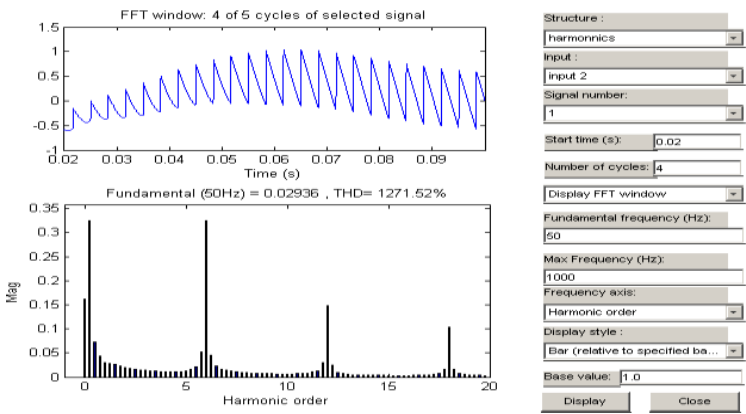

Fig. 4.10 Iq harmonics for rectifier load with APF

Inverter gating, reference and capacitor Current wave forms and THD with APF shown in Fig. 4.7 and Fig. 4.8, Id harmonics THD for rectifier load with APF and Iq harmonics THD for rectifier load with APF shown in Fig. 4.9 and Fig. 4.10 .

From the above THD value of Current it is clear that with Shunt APF control method Current wave form distortions reduced to $4.74 \%$ which is allowable range when compared to IEEE standard $5 \%$. Thus supply current distortions are greatly reduced from $29.04 \%$ for fixed diode rectifier load to $4.74 \%$ with SAPF control strategy

\section{CONCLUSIONS}

This control method is applied for non - linear loads which eliminate high distorted current harmonics to allowable range. This is very much applicable even when the load on the system frequently changes. Thus it provides good results for dynamic load changes. The harmonic currents, which need to be compensated, are directly calculated from the supply voltage thus this system is independent of the frequency. Hence it can be applied for any system irrespective of the frequency changes. The Instantaneous Active and Reactive current component (Id - Iq) control method provides efficient compensation of current harmonics of supply current waveform and uses a simple control strategy.

\section{REFERENCES}

[1] Gary W.Chang, "Harmonic Theory", National Chung University.

[2] N.M Pawar "Harmonics And Its Effects", From Eeu, NovDec 2006.

[3] Bhattacharya, D.Diwan And B.Banarjee "Active Filter System Implementation For Harmonic Eliminations" Ieee Industry Magazine Sept-Oct 1998.

[4] Suresh Kumar K.S "Active Power Techniques For Harmonic Elimination" Asst.Prof.Dept Of Electrical Engg, R.E.C Calicut.

[5] Vasco Soares, Pedro Verdelho, "An Instantaneous Active And Reactive Current Component Method For Active Filters". Ieee Tran, Power Electronics Vol 15, July-2000.

[6] S.Bhattacharya, D.Diwan And B.Banarjee "Synchronous Frame Harmonic Isolation Using Active Filters" In Proc, Epe'91 Conf.Vol 3, 1991.

[7] J.Dixon, G.Venegas And L.Morin, “A Simple Frequency Independent Method And Harmonic Current In A Non Linear Load", Ieee Trans, Ind 3, Power Electronics, Vol. 43.

[8] Lining Zhou ,"Evalution And Implementation Of Pwm Approaches".

[9] V.Soares And P.Verdelho, "Instantaneous Active And Reactive Current Id - Iq Calculation Suitable To Active Power Filters", In Proc, Power Electronics, Mar - 1998, Conf.Vol 7, 1998.

[10] "Power Electronics Circuits, Devices And Applications" By Muhammad H.Rashid. Publication From Prentice-Hall Of India. Year Of Publication: 2000.

K.Srinivas received the B.E. degree in electrical and electronics engineering from Chithanya Bharathi Institutue of Technology and Science, Hyderabad, Osmania University, Hyderabad, India, in 2002, the M.Tech. Degree in power systems and Power Electronics from the Indian Institute of Technology, Madras, Chennai, in 2005, pursuing Ph.D from Jawaharlal Nehru Technological University Hyderabad. Currently, he is an Assistant Professor in Electrical and Electronics Engineering Department, Jawaharlal Nehru Technological University Hyderabad College of Engineering Karimanagar. His fields of interest include power quality and power-electronics control in power systems.

Dr.S.S.Tulasi Ram received the B.Tech, M Tech and Ph.D Degrees in electrical and electronics engineering from Jawaharlal Nehru Technological University Hyderabad India, in 1979, 1981 and 1991rescpectively. Currently, he is a Professor in Electrical and Electronics Engineering Department, Jawaharlal Nehru Technological University Hyderabad College of Engineering Kukatpally, Hyderabad. His fields of interest include HVDC Transmission systems, Power system dynamics, Power Quality in power electronics, Smart energy management, 